\section{Missing the trends in the fentanyl overdose crisis: The need for immediate intervention in small and rural communities}

Dear Editor:

The province of British Columbia (BC), Canada, has been one of the first and most severely impacted jurisdictions by fatal fentanyl overdose events. ${ }^{1}$ Because a majority of publicized overdose fatalities occur in large urban municipalities such as Vancouver, the magnitude of cases occurring in small or rural areas is often overshadowed. ${ }^{2}$ For example, the health services delivery areas in BC that include small towns and rural communities, such as Fraser East, Fraser North, Central, and Northern Vancouver Island, have had fatal overdose cases that closely match in frequency with their urban counterparts of Vancouver Coastal and South Fraser. ${ }^{2}$ After taking into account the variances in population density, similar overdose trends are also reflected in the rural communities across North America, even prior to fentanyl's introduction into illegal markets. ${ }^{3}$

\section{WAYS FORWARD}

The rising mortality rate associated with the growing fentanyl overdose epidemic in small towns and rural jurisdictions may be attributed to numerous local factors, some of which are highlighted below. The rural areas' geographic isolation and their limited access to health centres have revealed that people who use drugs face a greater risk of morbidity and mortality. ${ }^{4}$ For example, in 2016, more than $60 \%$ of overdose cases in BC took place in a private dwelling. ${ }^{1}$ Moreover, drug users who reside in rural areas face legitimate concerns surrounding confidentiality and anonymity when accessing harm reduction services, placing these individuals at a greater risk of increased social isolation. ${ }^{5}$ In addition, rural drug users are more susceptible to financial burden when accessing services, due to a shortage of skilled health care professionals who are familiar with the unique health care needs of drug users. ${ }^{5}$

\section{NEXT STEPS}

There is an urgent need for investment from federal, provincial, and local governments in evidence-based health care models that focus on the unique needs of rural drug users. These investments can be facilitated by enhancing access to evidence-based harm reduction and treatment models. Health agencies must begin consulting the rural communities affected by drug use, in order for the root causes of stigma and discrimination to be properly addressed. In the meantime, national and local governments need to harness and reassert the already established harm reduction network in rural areas to address the growing epidemic of overdose cases, which inflict pain, suffering, and even further isolation in Canada's most vulnerable communities.

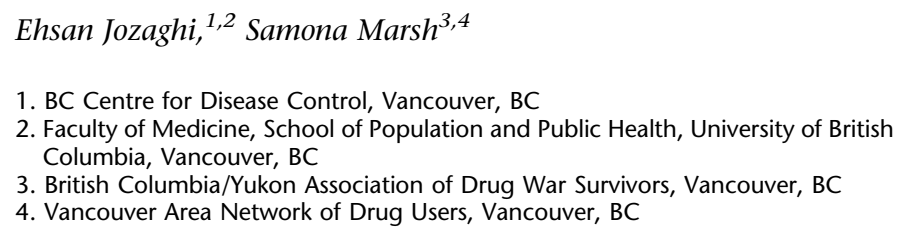

Correspondence: Ehsan Jozaghi, ehsan.jozaghi@ubc.ca

doi: 10.17269/CJPH.108.6480

\section{ACKNOWLEDGEMENTS}

We thank the Vancouver Area Network of Drug Users' (VANDU) board members for reading the earlier draft of this letter and appointing an author to work on this draft with the first author. We also thank Aiyanas Ormond and Caimen Yen for their assistance. The contribution by EJ was supported by a CIHR Postdoctoral Fellowship (201511MFE-358449-223266).

Conflict of Interest: The views expressed in this letter are those of the authors, and they may not necessarily express the views of the Canadian Institutes of Health Research or the BC Centre for Disease Control.

\section{REFERENCES}

1. Thomson E, Lampkin H, Maynard R, Karamouzian M, Jozaghi E. The lessons learned from the fentanyl overdose crises in British Columbia, Canada. Addiction 2017;112:2066-70. PMID: 28901045. doi: 10.1111/add.13961.

2. BC Coroners Service. Illicit Drug Overdose Deaths in BC: January 1, 2007-July 31 2017, 2017. Available at: http://www2.gov.bc.ca/assets/gov/public-safety-andemergency-services/death-investigation/statistical/illicit-drug.pdf (Accessed September 13, 2017).

3. Des Jarlais DC, Nugent A, Solberg A, Feelemyer J, Mermin J, Holtzman D. Syringe service programs for persons who inject drugs in urban, suburban, and rural areas - United States, 2013. MMWR Morb Mortal Wkly Rep 2015 64(48):1337-41. PMID: 26655918. doi: 10.15585/mmwr.mm6448a3.

4. Parker J, Jackson L, Dykeman M, Gahagan J, Karabanow J. Access to harm reduction services in Atlantic Canada: Implications for non-urban residents who inject drugs. Health Place 2012;18(2):152-62. PMID: 21955638. doi: 10. 1016/j.healthplace.2011.08.016.

5. McCutcheon JM, Morrison MA. Injecting on the Island: A qualitative exploration of the service needs of persons who inject drugs in Prince Edward Island, Canada. Harm Reduct J 2014;11(1):10. PMID: 24593319. doi: 10.1186/1477-7517-11-10. 